\title{
Early successional wildlife monitoring on reclamation plots in the Athabasca oil sands region
}

\author{
V.C. Hawkes LGL Limited Environmental Research Associates, Canada
}

\begin{abstract}
Assessing the effectiveness of reclamation efforts to create wildife habitat in the Athabasca oil sands region requires an assessment of wildlife use of reclaimed areas as well as the development of scientifically defensible and repeatable survey methods. The Cumulative Environmental Management Association (CEMA) is mandated to develop guidance documents for assessing reclamation effectiveness on oil sands leases. As part of a pilot study funded by CEMA to assess the use of early successional stands (i.e. those ranging in age from 4 to 17 years) by wildlife (songbirds, small mammals, and ungulates), a wildlife monitoring protocol was developed and field tested in 2010 and 2011. The purpose of this project was to (1) set standards upon which to base longer-term monitoring, and (2) identify wildlife groups that will indicate whether reclaimed ecosystems satisfy land use objectives, including the objective of returning wildife to reclaimed habitats. The study achieved the following goals: 1) an assessment of the return and reestablishment of early successional wildlife to reclaimed terrestrial systems; 2) an assessment of the feasibility of the recommended protocols for monitoring wildlife on reclaimed terrestrial systems; 3) the development of recommendations for the wildlife appendix of the Guidelines for Reclamation to Forest Vegetation in the Athabasca oil sands region for early successional wildlife monitoring based on the monitoring programme results; and 4) the collection of monitoring data to assist in identifying and developing wildlife indicators for reclamation certification. Early indications suggest that the proposed methods are suitable for documenting wildlife use of reclaimed plots; however, the frequency and duration of monitoring needs to be increased to determine patterns of re-establishment and use by wildlife. A history of the reclamation sites included in the pilot study is provided along with an overview of the current status and use of those sites by wildlife. Recommendations regarding the programme scope and changes to the monitoring protocol in terms of frequency, duration, and study design are made. Ultimately, comparisons between reclaimed and natural stands of similar age should provide the necessary data to determine if wildlife use in reclaimed plots is comparable to that in natural stands.
\end{abstract}

\section{Introduction}

Anthropogenic disturbances are occurring in the Athabasca oil sands region (AOSR), principally from surface mining, steam-assisted gravity drainage (SAGD), and conventional oil and gas development (AENV, 2010). Although the long-term impacts to wildlife and their habitats are unknown, the Guidelines for Reclamation to Forest Vegetation in the Athabasca oil sands region suggests reclaimed ecosystems should satisfy land use objectives, including the objective of returning wildlife to reclaimed habitats (AENV, 2010). To evaluate the success of ongoing reclamation efforts, direct observations of wildlife re-occupying reclaimed plots at various stages of vegetative succession are needed. Thus, a monitoring programme is required to assess the effectiveness of reclamation efforts to provide habitat for wildlife in the AOSR to determine if reclaimed habitats have habitat capabilities commensurate with those associated with the predisturbance condition. Effectiveness monitoring for wildlife should indicate how well the reclaimed ecosystems address the objectives of reclamation through an assessment of the interactions between wildlife and habitat elements believed to be important to those wildlife (Noss and Cooperrider, 1994; Morrison and Marcot, 1995).

An effectiveness monitoring programme should be designed to determine how well management activities, decisions, or practices meet the stated objectives of the programme being monitored (Marcot, 1998; Noon, 2003). Key to designing an effectiveness monitoring programme is the selection of statistically testable response variables appropriate to the objectives of the management action (Machmer and Steeger, 2002); however the selection of indicators (e.g. focal species) can be challenging (Andersen, 1999). The selection of 
indicator species/processes should be guided by their sensitivity to the management practice, the ease of collecting data, and the usefulness of the information to address the management activity (Chase and Guepel, 2005). Potential indicators may include habitat attributes, keystone species, species at risk, species associated with specific (sensitive) habitat requirements, or species that can be monitored easily (Feinsinger, 2001; Chase and Guepel, 2005); their selection should also be appropriate to the spatial scale of the applied management activity. The selection of indicators must also take into consideration factors external to the monitoring programme such as inter and intra-specific competition, predation, climatic change, disease, and seasonal variation in temperature and precipitation rates.

Because it is not practical to monitor all species of wildlife occurring in the AOSR, fourteen priority wildlife species and two bird guilds were selected to represent wildlife communities considered to be of ecological or socio-economic importance in the region. The fourteen species and two bird guilds were selected based on several criteria including their use as key indicator resources in environmental impact assessments as part of the project submission process under the Environmental Protection and Enhancement Act (EPEA) (AENV, 2010). These fourteen species and two bird guilds form the basis for discussions of habitat requirements and guide recommendations for reclamation of habitat in the AOSR. Because the effects of the various anthropogenic disturbances to wildlife populations and the ability for reclamation prescriptions to mitigate those impacts are unknown, an effectiveness monitoring programme is being implemented to assess the use of early succession reclamation plots by some or all of the fourteen species and two bird guilds.

This monitoring programme focuses specifically on reclaimed plots that are part of the long-term plot network, which was established in 2000 to understand the capability of reclaimed landscapes in the AOSR to return to forest cover patterns and processes equivalent to pre-disturbance conditions. Past wildlife monitoring efforts for this region include: 14 winter track surveys for mammals since 1997, a waterbird and waterfowl in wetlands survey in 2007, a raptor survey in 1999 with baseline data from 1976 and 1983, songbird point count surveys since 2002, amphibian breeding call surveys between 2000 and 2006, a Canadian toad telemetry study in 2005 to 2006, and species-at-risk surveys (AENV, 2010). This study added to these previous surveys by asking specifically whether wildlife are returning to and using reclaimed plots during early stages of succession. The purpose of this project was to (1) set standards upon which to base longer-term monitoring, and (2) identify wildlife groups that will indicate whether reclaimed ecosystems satisfy land use objectives (defined as the return of reclaimed habitats to pre-disturbance wildlife habitat capabilities), including the objective of returning wildlife to reclaimed habitats. This paper reports on the results of fall 2010 small-mammal trapping and winter snow-track transects and the applicability of these methods to monitor early successional wildlife use of reclamation plots on the AOSR.

\section{Methods}

\subsection{Project area}

Wildlife monitoring occurred on seven plots in the vicinity of Mildred Lake and the Athabasca River north of Fort McMurray, Alberta on leases operated by Suncor Energy $(n=2)$ and Syncrude Canada Ltd. $(n=5$; Figure 1). The seven plots included in the pilot programme are listed in Table 1. Field surveys were completed in fall 2010 and winter 2011. 


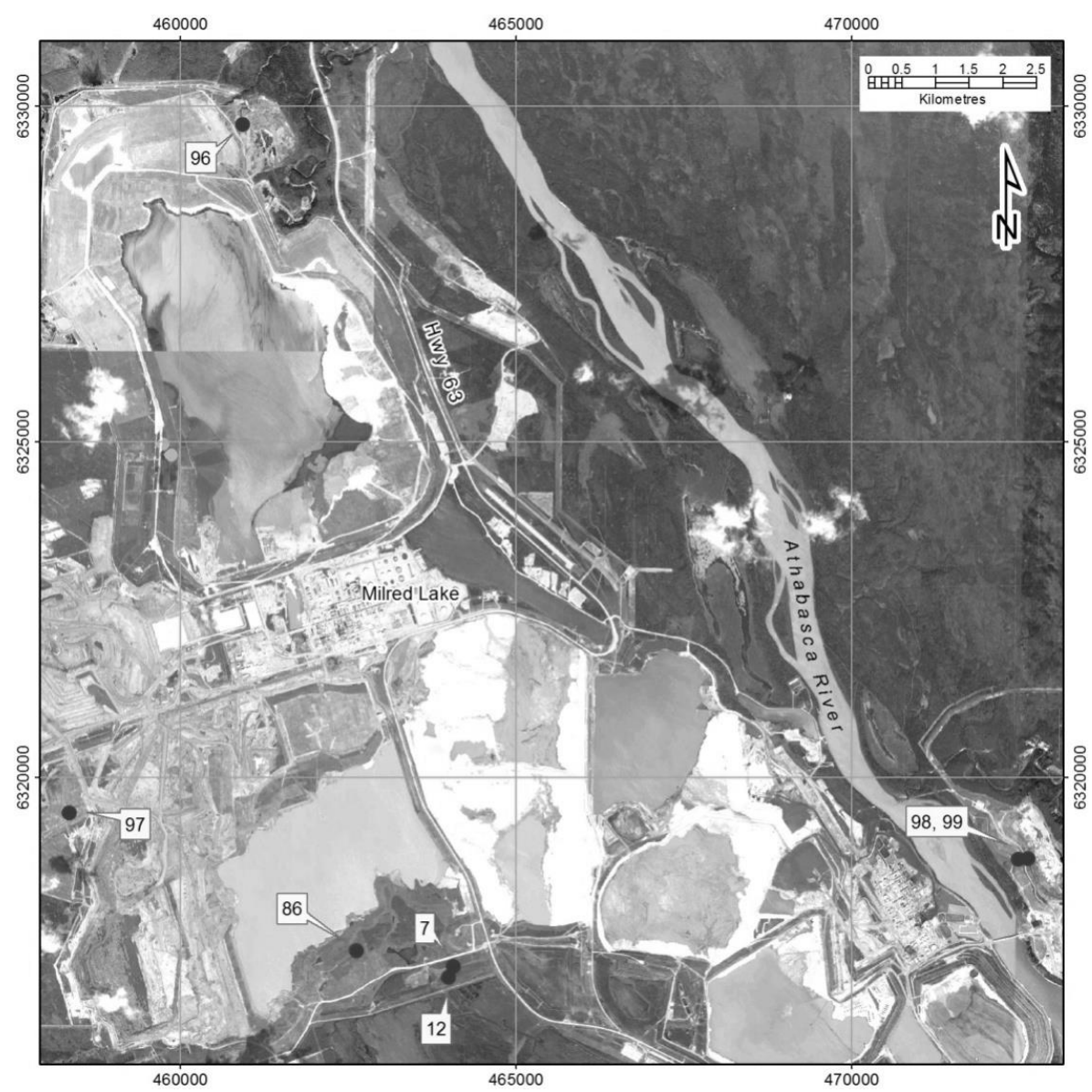

Figure 1 Distribution of plots sampled in the Athabasca oil sands region to assess use of early successional reclamation plots by wildlife. Plots 98, 99 = Suncor; 7, 12, 86, 96 and 97 = Syncrude. Image @ Google Earth 2010

Table 1 Characteristics of the seven plots included in the pilot study to assess early successional wildlife use of reclaimed plots in the Athabasca oil sands region

\begin{tabular}{|c|c|c|c|c|c|c|c|c|}
\hline Plot No. & Lease & $\begin{array}{c}\text { Reclamation } \\
\text { Area (ha) }\end{array}$ & $\begin{array}{c}\text { Dominant } \\
\text { Habitat }\end{array}$ & $\underset{(\mathbf{y r s})^{1}}{\text { Age }}$ & SMR & SNR & Drainage & $\begin{array}{c}\text { Tree } \\
\text { Species }^{2}\end{array}$ \\
\hline 98 & Suncor & 31.4 & $\begin{array}{l}\text { Pure } \\
\text { Spruce }\end{array}$ & 4 & Mesic & Rich & Well & $\mathrm{Sw}(90 \%) \mathrm{Bw}(10 \%)$ \\
\hline 99 & Suncor & 33.8 & Pure Aspen & 4 & Mesic & Rich & Well & $\operatorname{At}(85 \%) \mathrm{Sw}(15 \%)$ \\
\hline 7 & Syncrude & $\mathrm{NA}^{3}$ & $\begin{array}{l}\text { Pure } \\
\text { Spruce }\end{array}$ & 16 & Submesic & Medium & Well & Sw $(100 \%)$ \\
\hline 12 & Syncrude & NA & $\begin{array}{l}\text { Spruce \& } \\
\text { Deciduous }\end{array}$ & 17 & Submesic & Poor & Well & At $(70 \% \mathrm{Sw}(30 \%$ \\
\hline 86 & Syncrude & NA & Aspen & 7 & Mesic & Medium & Mod. Well & At (80\%) Sw (20\%) \\
\hline 96 & Syncrude & NA & $\begin{array}{l}\text { Pure Pine } \\
\text { or Pine + } \\
\text { Deciduous }\end{array}$ & 4 & Subxeric & Rich & Rapidly & $\mathrm{Pj}(100 \%)$ \\
\hline 97 & Syncrude & NA & $\begin{array}{l}\text { Pure } \\
\text { Spruce }\end{array}$ & 4 & Mesic & Rich & Mod. Well & Sw $(100 \%)$ \\
\hline
\end{tabular}

1 Age since reclamation. $2 \mathrm{Sw}=$ White Spruce; $\mathrm{Bw}=$ White Birch; At = Trembling Aspen; $\mathrm{Pj}=$ Jack Pine. 3 NA data were not available at the time of paper submission. Note: $\mathrm{SMR}=$ soil moisture; $\mathrm{SNR}=$ soil nutrients. 


\subsection{Wildlife sampling}

Wildlife selected for monitoring included small mammals, ungulates (moose; Alces americanus), ruffed grouse (Bonasa umbellus), Lynx (Lynx canadensis), snowshoe hare (Lepus americanus), and mixed-wood songbirds (results not reported in this paper). These species or species groups were sampled in each of the seven plots using a standardised experimental unit that consisted of a $500 \mathrm{~m}$ long snow-track transect, a $100 \mathrm{~m}^{2}$ small mammal sampling grid, and two $75 \mathrm{~m}$ variable-radius point count stations situated at each end of the $500 \mathrm{~m}$ transect (Figure 2). This design was used to ensure that wildlife data collected within a given reclamation plot could be attributed to a given suite of reclamation plot characteristics (Table 1). Although edge effects are likely to influence wildlife use of the reclamation plots (e.g. Yahner, 1988; Mills, 1995), the experimental unit was placed in the approximate centre of each reclamation plot in an attempt to minimise edge effects.

Small mammal live-trapping occurred in fall 2010 using a combination of Sherman and Little-Critter (Longworth style) traps baited with peanut butter and oats. Raw cotton was placed in the traps to provide bedding material for captured small mammals. Tomahawk traps were used to target small and medium-sized carnivores [e.g. short-tailed weasel (Mustela erminea) and red fox (Vulpes vulpes)], scented with a combination of skunk oil, beaver castor, marten and fisher lure, and anise oil combined in a glycerine base. Sherman and Little-Critter live traps were arranged in a $7 \times 7$ grid, with traps placed at $16.7 \mathrm{~m}$ intervals. Tomahawk Traps (one large and one small) were situated $\sim 100 \mathrm{~m}$ from one edge of the trapping grid. Traps were checked once daily (or twice depending on the ambient temperature) and all captured small mammals were identified to species, assigned to an age class (juvenile, sub-adult, or adult), weighed to the nearest 0.1 gram (using a Pesola ${ }^{\circledR}$ scale), ear tagged, assigned as male, female, or unknown, and released. Animals trapped in Tomahawk traps were identified to species and released. Trapping data were standardised to the number of catches per 100 trap nights as a measure of relative abundance for each species adjusted for missed nights or non-functional traps (Nelson and Clark, 1973). Trap night totals were a function of trap status where traps that were functional and baited on the day of the check were attributed one trap night. Traps that were closed, missing bait, not functional for some other reason, or missing, were assigned 0.5 trap nights. Similarly, for traps that captured an animal, a value of 0.5 trap night was assigned.

Snow-tracking occurred during early February 2011 and each $500 \mathrm{~m}$ transect was traversed once. All mammal and bird (grouse) sign (e.g. tracks, pellets, and beds) was recorded as on or off transect. Observations within $2 \mathrm{~m}$ of the transect were considered to be on transect. Snow depth and condition was measured from six locations along each transect as were the general environmental conditions encountered during the survey.

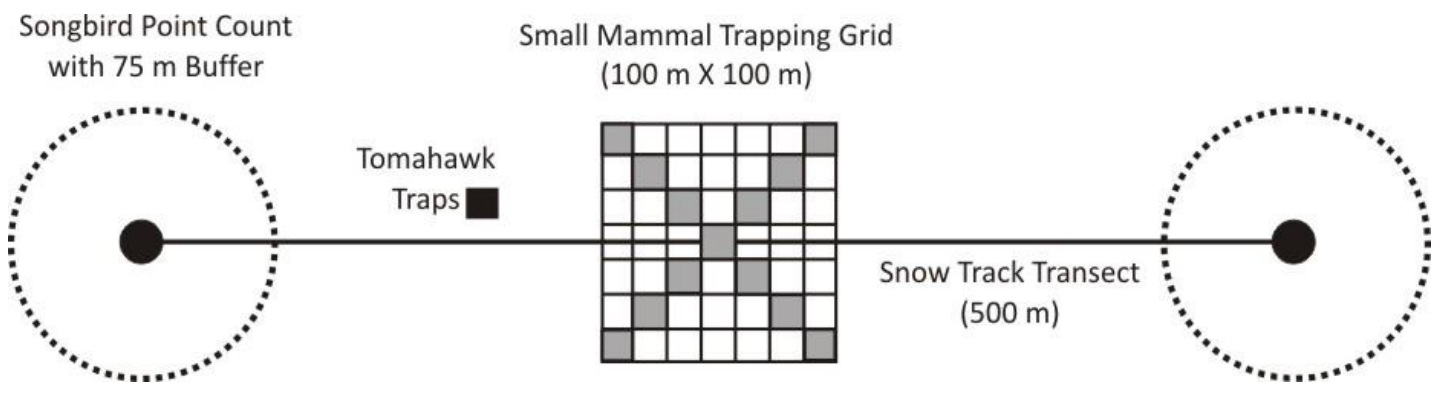

Figure 2 Schematic of experimental design used to sample for early successional wildlife on reclamation plots in the Athabasca oil sands region. Shaded cells in the small mammal tapping grid indicate the location of Little-Critter Traps; unshaded cells indicate Sherman trap locations

\subsection{Data analyses}

Because this is a pilot study to test the efficacy of the proposed methods to document wildlife use of early successional reclamation plots, data analyses were limited and only graphical and tabular summaries of the data are provided. The total number of mammal and bird species documented per plot is reported. Small mammal trapping and snow track data were standardised to either a catch per unit effort (catch per 100 trap nights) for small mammals or to track density (number of tracks per $100 \mathrm{~m}$ ) for snow track surveys. 


\section{$3 \quad$ Results}

\subsection{Fall 2010 small mammal trapping}

Small mammal trapping occurred between 23 September and 06 October 2010 for a total of 3,798 trap nights (all trap types combined). Total trapping effort varied by reclamation plot and was largely a function of the total nights trapped per site $(\min =445.5 ; \max =628$; mean $=542.5$ nights per site $)$. During fall 2010, 508 captures of animals were made on the small mammal trapping grids. The vast majority $(n=499)$ were mammals; the remaining nine were birds [Black-billed Magpie (Pica hudsonia), Gray Jay (Perisoreus canadensis), and Lincoln's Sparrow (Melospiza lincolnii)]. The mammals captured were: Coyote (Canis latrans), Meadow Vole (Microtus pennsylvanicus), Short-tailed Weasel, Least Weasel (Mustela nivalis), Southern Red-backed Vole (Myodes gapperi), Deer Mouse (Peromyscus maniculatus), Arctic Shrew (Sorex arcticus), Shrew species (Sorex sp.) and Red Squirrel (Tamiasciurus hudsonicus).

The 499 mammal captures represented 198 individuals. The remaining 301 captures were either recaptures $(n=296)$ or it was unknown if the individual had been previously marked $(n=5)$. The relationship between trap effort and species captures is shown in Figure 3 and has been calculated using the total trap nights amassed for all seven plots. This enabled a comparison of the relative abundance (catch per unit effort or CPUE) of each species captured relative to total trap effort. Certain species (Coyote, Least Weasel and Arctic Shrew) were caught only once and therefore have the lowest CPUE of all species. Deer Mouse (PEMA) was the most abundant species followed by Meadow Vole (MIPE) and Southern Red-backed Vole (MYGA). Shrews (unidentified species) and Red Squirrels were present, but not on every site and in relatively low numbers (Table 2).

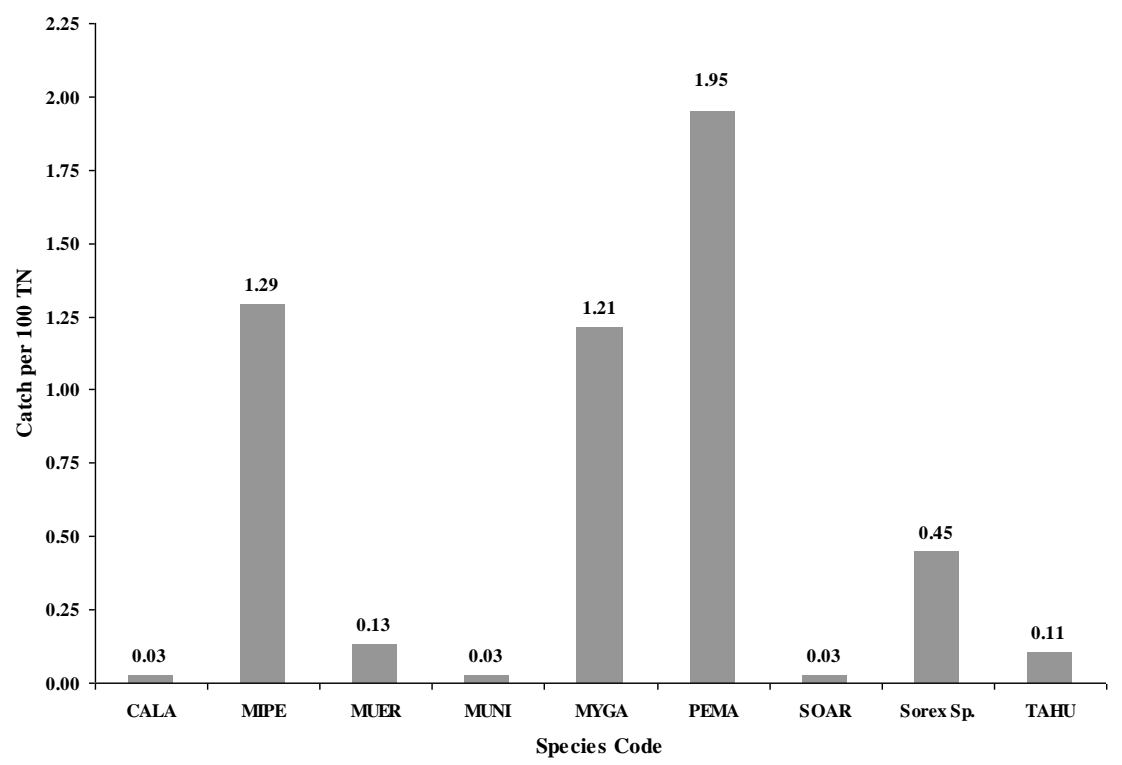

Figure 3 Comparison of the catch per unit effort (catches per 100 trap nights) for all species captured on all seven reclamation plots in fall 2010. The catch per unit effort was calculated for unique individuals only (i.e. recaptures were excluded). CALA $=$ Canis latrans; MIPE = Microtus pennsylvanicus; MUER = Mustela erminea $;$ MUNI = Mustela nivalis; MYGA = Myodes gapperi; PEMA = Peromyscus maniculatus; SOAR = Sorex arcticus; Sorex sp. = Sorex species; TAHU = Tamiasciurus hudsonicus.

The reclamation plots sampled in fall 2010 varied with respect to the total number of species and total catch per unit effort (all species and trap types combined; Table 2). Sites in proximity to one another (e.g. 98 and 99; 7, 12, and 86; Figure 1) did not always have the same catch per unit effort or number of species. For example, the variation among sites 7,12 , and 86 was likely related to vegetation cover and not necessarily a function of effort (given that all data have been corrected to account for the variation in total trap nights per 
site). The relationship between species presence and vegetation cover is not yet clear and requires further investigation, which will occur when more data are obtained.

Table 2 Relative abundance (catch per 100 trap nights) of mammal species trapped on each permanent sample plot in fall 2010. Species codes as per Figure 3

\begin{tabular}{|c|c|c|c|c|c|c|c|c|c|c|c|}
\hline \multirow[b]{2}{*}{$\begin{array}{c}\text { Site } \\
\text { Number }\end{array}$} & \multirow[b]{2}{*}{$\begin{array}{c}\text { Trap } \\
\text { Nights }\end{array}$} & \multicolumn{9}{|c|}{ Species Code } & \multirow[b]{2}{*}{ Species } \\
\hline & & CALA & MIPE & MUER & MUNI & MYGA & PEMA & SOAR & $\begin{array}{c}\text { Sorex } \\
\text { sp. }\end{array}$ & TAHU & \\
\hline 7 & 549.5 & 0.0 & 0.0 & 0.0 & 0.0 & 2.0 & 2.0 & 0.0 & 0.2 & 0.4 & 4 \\
\hline 12 & 505.5 & 0.0 & 0.0 & 0.4 & 0.0 & 3.8 & 2.4 & 0.0 & 0.6 & 0.2 & 5 \\
\hline 86 & 591 & 0.0 & 2.5 & 0.5 & 0.2 & 2.0 & 0.0 & 0.2 & 1.0 & 0.2 & 7 \\
\hline 96 & 559 & 0.2 & 0.2 & 0.0 & 0.0 & 0.5 & 1.1 & 0.0 & 0.2 & 0.0 & 5 \\
\hline 97 & 628 & 0.0 & 0.0 & 0.0 & 0.0 & 0.0 & 0.3 & 0.0 & 0.2 & 0.0 & 2 \\
\hline 98 & 445.5 & 0.0 & 1.6 & 0.0 & 0.0 & 0.0 & 6.5 & 0.0 & 0.2 & 0.0 & 3 \\
\hline 99 & 519.5 & 0.0 & 5.0 & 0.0 & 0.0 & 0.2 & 2.7 & 0.0 & 0.8 & 0.0 & 4 \\
\hline Totals & 3,798 & 1 & 4 & 2 & 1 & 5 & 6 & 1 & 7 & 3 & \\
\hline
\end{tabular}

When considering all species documented per plot, the two sites on the east side of the Athabasca River (sites 98 and 99) had the highest catch per unit effort (including recaptures) followed by sites 12, 86, 7, 96, and 97 (Figure 4). Interestingly, sites 96, 97, 98, and 99 were reclaimed 4 years ago while the others were reclaimed between 7 and 17 years ago (Table 1). It is likely that the proximity to adjacent forested habitat has influenced the return of wildlife species to these plots. For example, plots 98 and 99 are situated close to continuous forested habitat while sites 96 and 97 vary in their proximity to adjacent suitable habitat with site 97 surrounded almost entirely by developed areas (Figure 1). The influence of edge effects have not been investigated as part of this pilot study, but are likely to have some influence on wildlife use of certain reclamation plots.

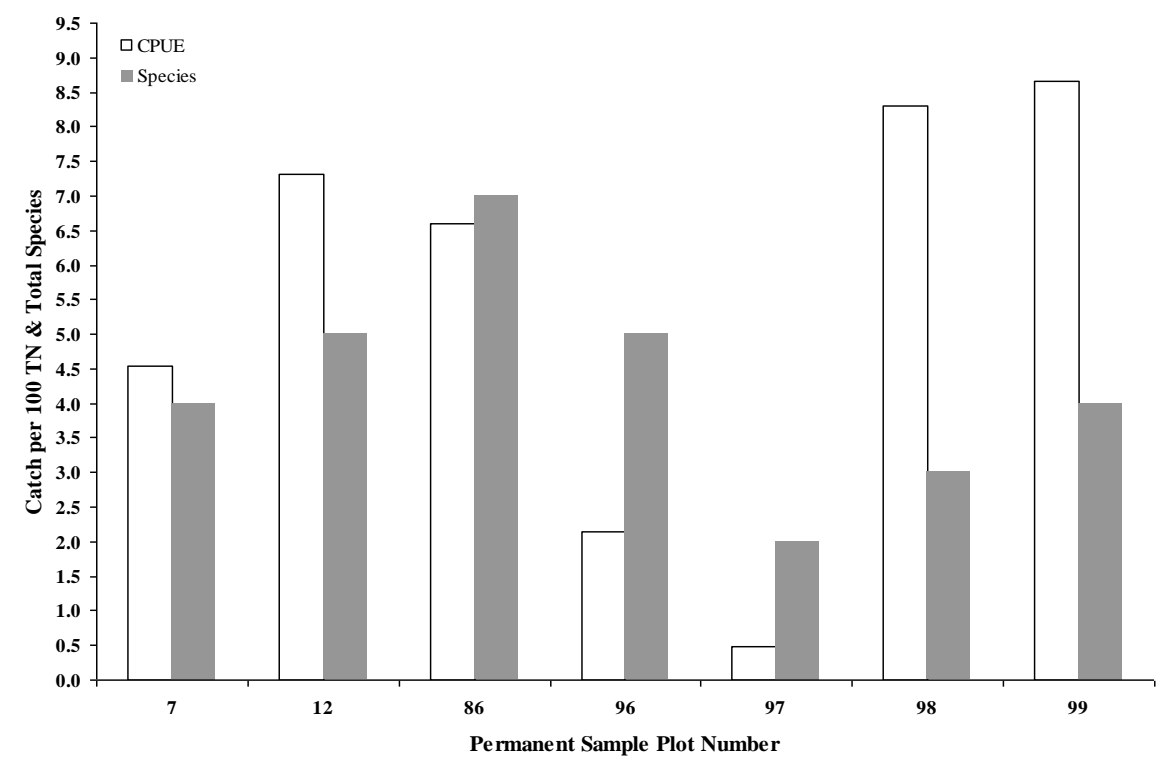

Figure 4 Total catch per unit effort (all captures and recaptures included) and total species captured per reclamation plot (all trap types combined) in fall 2010 


\subsection{Winter 2011 snow-track transects}

Wildlife observations were classified to species or genus with 13 species and three genera detected (Table 3). The number of wildlife species (i.e. mammals and birds) observed on each reclamation plot ranged from two to seven. The distribution of wildlife relative to reclamation plot indicates that wildlife species do not appear to be uniformly distributed across the plots, which could be a function of survey effort (only one visit to each snow track transect), or as stated above, a function of the proximity of the plots to adjacent suitable habitat.

Table 3 Wildlife species documented at each reclamation plot during winter 2011 snow track surveys

\begin{tabular}{|c|c|c|c|c|c|c|c|c|c|c|}
\hline & \multirow[b]{2}{*}{ Common Name } & \multirow[b]{2}{*}{ Scientific Name } & \multicolumn{7}{|c|}{ Plot Number } & \multirow[b]{2}{*}{ Total Species } \\
\hline & & & 7 & 12 & 86 & 96 & 97 & 98 & 99 & \\
\hline \multirow{10}{*}{ 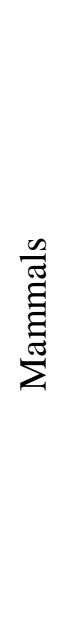 } & Moose & Alces americanus & & 1 & 1 & 1 & & 1 & & 4 \\
\hline & Coyote & Canis latrans & & & 1 & & & & & 1 \\
\hline & Gray wolf & Canis lupis & & & & & 1 & & & 1 \\
\hline & Canid species & Canis sp. & & & & 1 & & & 1 & 2 \\
\hline & Snowshoe hare & Lepus americanus & 1 & 1 & 1 & 1 & & & & 4 \\
\hline & Short-tailed weasel & Mustela erminea & & 1 & & & & & & 1 \\
\hline & Deer species & Odocoileus sp. & & & & 1 & & & & 1 \\
\hline & Deer mouse & Peromyscus maniculatus & & & & & & 1 & & 1 \\
\hline & Red squirrel & Tamiasciurus hudsonicus & 1 & & & & & & & 1 \\
\hline & Red fox & Vulpes vulpes & & & 1 & 1 & 1 & & 1 & 4 \\
\hline \multirow{7}{*}{$\stackrel{0}{0}$} & Common raven & Corvus corax & & 1 & & & & & & 1 \\
\hline & Grey jay & Perisoreus canadensis & & 1 & & & & & & 1 \\
\hline & Black-billed magpie & Pica hudsonia & & 1 & 1 & & & & & 2 \\
\hline & Woodpecker species & Picoides sp. & & & 1 & & & & & 1 \\
\hline & Snow bunting & Plectrophenax nivalis & & & & & 1 & & & 1 \\
\hline & Sharp-tailed grouse & Tympanuchus phasianellus & & & 1 & & & & 1 & 2 \\
\hline & & Total Species & 2 & 6 & 7 & 5 & 3 & 2 & 3 & \\
\hline
\end{tabular}

Note: Species listed in this table were indentified through sign (tracks scat, beds) or observed on each plot. ' 1 ' indicates detection; blanks indicate non-detection.

Estimates of relative abundance were calculated for those species for which track data were obtained. Track density was calculated as the number of tracks per species per $100 \mathrm{~m}$. Given that only one snow track survey was completed in 2011, the results are likely not indicative of the actual distribution of each species across the plots sampled; however, we did document the presence of six species of wildlife (Table 4). The density of moose tracks was highest on plot 86 followed by plots 96 and 12 . 
Table 4 Track density (number of tracks/100 m) on each permanent sample plot surveyed in winter 2011

\begin{tabular}{lccccccc}
\hline & \multicolumn{7}{c}{ Permanent Sample Plot Number } \\
Species & $\mathbf{7}$ & $\mathbf{1 2}$ & $\mathbf{8 6}$ & $\mathbf{9 6}$ & $\mathbf{9 7}$ & $\mathbf{9 8}$ & $\mathbf{9 9}$ \\
\hline Canis sp. & 0.00 & 0.00 & 0.00 & 0.20 & 0.00 & 0.00 & 0.40 \\
Canis latrans & 0.00 & 0.00 & 0.20 & 0.00 & 0.00 & 0.00 & 0.00 \\
Peromyscus maniculatus & 0.00 & 0.00 & 0.00 & 0.00 & 0.00 & 0.60 & 0.00 \\
Alces americanus & 0.00 & 1.00 & 3.60 & 2.20 & 0.00 & 0.20 & 0.00 \\
Vulpes vulpes & 0.00 & 0.00 & 0.40 & 0.40 & 0.40 & 0.00 & 0.40 \\
Mustela erminea & 0.00 & 1.00 & 0.00 & 0.00 & 0.00 & 0.00 & 0.00 \\
Lepus americanus & 1.00 & 2.60 & 0.20 & 1.80 & 0.00 & 0.00 & 0.00 \\
Ungulate sp. & 0.00 & 0.00 & 0.00 & 0.80 & 0.00 & 0.00 & 0.00 \\
\hline Total Species & $\mathbf{1}$ & $\mathbf{3}$ & $\mathbf{4}$ & $\mathbf{5}$ & $\mathbf{1}$ & $\mathbf{2}$ & $\mathbf{2}$ \\
\hline
\end{tabular}

\section{$4 \quad$ Discussion and conclusions}

The results of this pilot programme indicate that wildlife are returning to and using reclaimed terrestrial systems in the AOSR. Specifically, several of the key indicator resources identified by AENV (2010) were documented on the plots sampled in 2010 and 2011. Although only one round of small mammal trapping and one winter track transect was completed per plot, the methods used were sufficient for documenting the presence of several key species including moose, snowshoe hare, and red-backed vole. It is likely that additional key indicator resources will be identified during spring small mammal and songbird sampling on the reclamation plots.

Based on the detection of several of the 14 key indicator resources with relatively little effort, the methods proposed for sampling early successional wildlife on reclamation plots in the AOSR appear to be appropriate. The methods implemented are commonly used techniques that are relatively easy to use and are also cost-effective. Because the experimental unit used to sample the various wildlife groups was standardised to sample the same area across each plot it will be possible to make direct comparisons of the relative abundance of wildlife among plots using a variety of stratification approaches. For example, it will be possible to compare the relative abundance of wildlife among plots of similar reclamation age, by reclamation type, edaphic conditions, or leading tree species.

Early indications suggest that the proposed methods are suitable for documenting wildlife use of reclaimed plots; however, the frequency and duration of monitoring needs to be increased to determine patterns of reestablishment and use by wildlife. To provide recommendations for the wildlife appendix of the Guidelines for Reclamation to Forest Vegetation in the Athabasca oil sands region for early successional wildlife monitoring based on the monitoring programme results requires additional data. However, based on these preliminary results, it is recommended that the monitoring programme be expanded to include natural plots that form part of the long-term plot network so that the diversity and richness of wildlife using reclaimed plots can be compared to those using natural (mature) stands in the AOSR. Without the inclusion of natural plots into the monitoring programme there is no way of knowing whether the reclaimed ecosystems are on a trajectory towards pre-disturbance wildlife habitat capabilities.

The collection of wildlife data on reclaimed plots in the AOSR may be suitable for identifying and developing wildlife indicators for reclamation certification. However, the ability to determine which species may function as suitable wildlife indicators that can be used to assess the relationship between reclamation success and wildlife use or return to reclaimed terrestrial systems is presently limited. To identify suitable wildlife indicators there needs to be an understanding of how wildlife use on reclamation plots can be correlated to reclamation type, time since reclamation, and a projection of how wildlife use will change 
relative to vegetation succession. To facilitate this understanding, wildlife sampling should occur on natural stands of varying age since disturbance (e.g. logging or fire) so that the wildlife use of a reclamation plot of a given age can be related directly to a natural stand of similar age. This will provide the data necessary to assess whether wildlife use of the reclaimed plots is similar to that in natural stands, and if so, a level of success regarding reclamation efforts can be assigned to the reclamation plot. Similarly, sampling should also occur in natural, mature stands to determine if changes in the detectability or relative abundance of the key indicator resources detected on reclamation plots are treatment effects or if the changes are indicative of a broader, regional shift in the detectability or relative abundance of one or more of the key indicator species being studied. Consideration of the effects of other potentially confounding variables such as climatic change, disease, and seasonal variation in temperature and precipitation rates on the detectability or relative abundance of one or more of the key indicator species should also form part of future data analyses aimed at assessing the use of reclaimed plots by early successional wildlife species.

Some species of wildlife are using the early successional reclamation plots with little indication (at present) that use is a function of stand age (i.e. time since reclamation); however, the correlation between wildlife use, reclamation type, reclamation area (hectares), and time since reclamation needs to be assessed over the long term by expanding the scope of the early successional wildlife monitoring programme to include more reclamation plots and natural plots of similar age since disturbance. To properly characterise the wildlife populations associated with each plot, annual sampling for three to five years, followed by bi-annual sampling for a minimum of a ten year period is suggested. This should provide the data necessary to characterise the natural variation associated with the relative abundance or detectability of each wildlife species or group being monitored and to assess the longer-term relationship between wildlife and their use of and/or return to reclaimed terrestrial systems in the Athabasca oil sands region.

\section{Acknowledgements}

This project was completed under contract to the Cumulative Environmental Management Association. Kyle Harrietha of CEMA administered the contract and Dr Gillian Donald provided technical input. Suncor Canada provided data on the area of the reclaimed plots sampled in this pilot programme. Jeremy Gatten, Janean Sharkey, Jamie Fenneman, Krysia Tuttle and Robin Tamasi of LGL Limited assisted with this project. The efforts of Dr Tim Edgell during the early stages of this project are appreciated.

\section{References}

Alberta Environment (AENV) (2010) Guidelines for Reclamation to Forest Vegetation in the Athabasca Oil Sands Region, 2nd Edition, Prepared by the Terrestrial Subgroup of the Reclamation Working Group of the Cumulative Environmental Management Association, Fort McMurray, AB.

Andersen, A.N. (1999) My bioindicator or yours? Making the selection, Journal of Insect Conservation, Vol. 3, pp. 61-64.

Chase, M.K. and Guepel, G.R. (2005) The Use of Avian Focal Species for Conservation Planning in California, USDA Forest Service General Technical Report PSW-GTR-191, pp. 130-142.

Feinsinger, P. (2001) Designing field studies for biodiversity conservation, Island Press, Washington, DC.

Machmer, M. and Steeger, C. (2002) Effectiveness Monitoring Guidelines for Ecosystem Restoration, Ministry of Environment, Victoria, BC, 18 p.

Marcot, B.G. (1998) Selecting appropriate statistical procedures and asking the right questions: a synthesis, V. Sit and B. Taylor (eds), Statistical methods for adaptive management, Research Branch, B.C. Ministry of Forests, Victoria, B.C.

Mills, L.S. (1995) Edge effects and isolation: red-backed voles on forest remnants, Conservation Biology, Vol. 9, pp. 395-403.

Morrison, M.L. and Marcot, B.G. (1995) An evaluation of resource inventory and monitoring program used in national forest planning, Environmental Management, Vol. 19, pp. 147-156.

Nelson Jr., L. and Clark, R.W. (1973) Correction for sprung traps in catch/effort calculations of trapping results, Journal of Mammalogy, Vol. 54, pp. 295-298.

Noon, B.R. (2003) Conceptual issues in monitoring ecological resources, D.E. Busch and J.C. Trexler (eds), Monitoring Ecosystems: Interdisciplinary Approaches for Evaluating Ecoregional Initiatives, Island Press, Washington.

Noss, R.F. and Cooperrider, A.Y. (1994) Saving Nature's Legacy: Protecting and Restoring Biodiversity, Island Press, Washington, DC, $380 \mathrm{p}$.

Yahner, R.H. (1988) Changes in wildlife communities near edges, Conservation Biology, Vol. 2, pp. $333-339$. 
